\title{
Vajinal Doğum Sonrası Plasentanın Kendiliğinden Ayrılma Zamanının ve Bu Süreyi Etkileyen Faktörlerin Belirlenmesi
}

\author{
Determining the Time of Spontaneous Separation of Placenta
}

and the Factors Affecting This Time After Vaginal Delivery

\author{
Nihat FARISOĞULLARI ${ }^{1}$, Zehra Meltem PİRIMOĞLU ${ }^{2}$ \\ Ali Doğukan ANĞIN ${ }^{2}$, Önder SAKİN ${ }^{2}$, Muzaffer Seyhan ÇIKMAN ${ }^{2}$, Ramazan DENIZLLI ${ }^{2}$ \\ 1. Viranşehir Devlet Hastanesi, Kadın Hastalıkları ve Doğum Kliniği, Şanlıurfa, Türkiye \\ 2. Dr. Lütfi Kırdar Kartal Ĕ̆itim ve Araştırma Hastanesi, Kadın Hastalıkları ve Doğum Kliniği, İstanbul, Türkiye
}

\section{$\ddot{O Z E T}$}

Amaç: Bu çalıșanın amacı, vajinal doğum sonrası plasentanin kendiliğinden ayrlma zamanını ve bu süreyi etkileyen faktörleri belirlemektir.

Gereçler ve Yöntem: Çalışmamıza İstanbul Dr. Lütfi Kırdar Kartal Eğitim ve Araștırma Hastanesi Kadın Hastalıklarl ve Doğum kliniğine 01.03.2016-01.01.2017 tarihleri arasinda vajinal doğum için başvuran 198 hasta dahil edildi. Vajinal doğumu takiben plasentanin kendiliğinden ayrlması beklendi ve 5 'er dakika aralıklarla kontrol edildi.

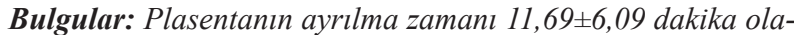
rak tespit edildi. Indüksiyon alan ve daha önce doğum yapmış hastalarda plasenta avrılma zamanının kısaldı ̌̆ görüldü. Hastaların \%96'sının plasentasının ilk 20 dakika içerisinde ayrıldiğg izlendi. 198 hastanın 5 'inde plasenta 30 dakika içerisinde kendiliğinden ayrılmadı ve elle halas edildi.

Sonuç: Bu çalışmada plasentanın kendiliğinden ayrılma süresi 10-15 dk. aralığında izlendi. Plasentanın kendiliğinden ayrllmast için eşik değerin 20 dk olarak tespit edilebileceği düşünüldü. Indüksiyon almak ve daha önce doğum yapmakta bu süreyi kısaltan faktörler olarak tespit edildi.

Anahtar Kelimeler: doğum evreleri, plasenta, retansiyon

\section{ABSTRACT}

Objective: The purpose of this study is to determine the timing of spontaneous separation of placenta after vaginal delivery and the factors affecting this time.

Material and Methods: Between 01.03.2016-01.01.2017 in the department of Obstetrics and Gynecology in Istanbul Dr. Lütfi Kirdar Kartal Education and Research Hospital.198 patients referred for vaginal delivery were included in our study. Following vaginal delivery, the placenta was expected to be spontaneously separated and checked at intervals of 5 minutes.

Results: The separation time of the placenta was determined

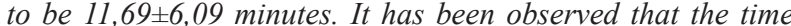
for placental separation in induction-receiving and previously delivered patients is shortened. The placenta of $96 \%$ of the patients left within the first 20 minutes. In 5 of 198 patients the placenta did not spontaneously separate within 30 minutes and was taken by hand.

Conclusion: In this study, the spontaneous separation time of the placenta was observed at intervals of 10-15 minutes. It was thought that 20 minutes should be determined as the threshold value for the spontaneous separation of the placenta. Taking induction and previously giving birth has been identified as a shortening factor.

Keywords: placenta, labor stages, retention

iletişim:

Sorumlu Yazar: Ali Doğukan ANĞIN

Adres: Dr. Lütfi Kırdar Kartal Eğitim ve Araştırma Hastanesi, Kadın Hastalıkları ve Doğum Kliniği, İstanbul, Türkiye

Tel: +90 (505) 6232027

E-Posta: dralidogukan@gmail.com

Makale Geliş: 06.04.2018

Makale Kabul: 06.10.2018

DOI: http://dx.doi.org/10.16948/zktipb.413370

\section{GÍRIS}

Plasenta ve eklerinin ayrilma zaman1, doğumun 3.evresinde gerçekleşmektedir. Maternal ölümlerin en sık nedenleri arasında sayılan postpartum kanamanın bu dönemde görülmesinden dolayı büyük önem arz etmektedir. Uzamış üçüncü evrenin en önemli riski kanamadır, bu risk süre ne kadar uzarsa o kadar artar $(1,2)$.

Literatürde plasentanın kendiliğinden ayrılma zamanını çalışmalar çok kısıtlıdır. Son 50 yıldır geleneksel olarak ama herhangi bir prospektif toplanmış bir veriye dayanmadan, plasentanın ayrılma süresi 30 dakika olarak kabul edilmektedir. Buna dayanarak plasentanın kendiliğinden ayrılma zamanı 30 dakikalara varan sürelerde beklenmekte, bu durum doğumun 3. fazını ve lohusa kadının kaybettiği kan miktarını bazı doğumlarda arttırmaktadır. Doğumun üçüncü evresinde 30 dakikadan sonra postpartum kanama riskinde anlamlı artış olur ve bu nedenle 30 ile 60. dakikalar arasında plasentanın doğumu için aktif müdahale akılcı gözükmektedir (3).

Amacımız, doğumun 3. Evresinde plasentanın herhangi bir müdahalede bulunulmaksızın kendiliğinden ayrılması için beklenilen süreyi gözden geçirmek, geçerli bir eşik zaman değeri bulmak ve bu süreyi etkileyen gebelik sayıs1, bebeğin kilosu gibi çeşitli faktörleri incelemektir. Plasentanın ayrılma süresini için gereğinden fazla beklenmesi engellenip kanama miktarının ve doğum sonrası gereksiz müdahaleleri azaltılması için bu eşik değer kullanılabilir.

\section{GEREÇ ve YÖNTEM}

Çalışmamız İstanbul Dr. Lütfi Kırdar Kartal Eğitim ve Araştırma Hastanesi Kadın Hastalıkları ve Doğum kliniğinde 01.03.2016-01.01.2017 tarihleri arasında yapıldı. Çalışma Hastane Etik Komitesi tarafından onaylandı. Tüm olgular çalışma öncesi çalışma hakkında bilgilendirilerek dolduracakları formlar ve vajinal yolla doğum hakkında detaylı bilgiler verilerek aydınlatılmış onamları alındı.

Prospektif gözlemsel planladığımız çalışmaya baş geliş ile tekil canlı vajinal doğumu gerçekleşen, 1549 yaş arası hastalar dahil edildi. Plasenta yerleşim ve yapışma anomalileri (plasenta previa, akreata, inkreata, perkreata) varlığ 1 , maternal enfeksiyon 
bulgusu veya semptomları olmas1, uterin anomali mevcudiyeti, koagülasyon defekti olması, müdahaleli doğum gerçekleşmesi(vakum/forceps), antikoagülan ilaç kullanımı, tokolitik kullanımı, sezaryen yada uterin cerrahi özgeçmişi olasn hastalar ve kan basıncının 140/90 mmHg veya üzerinde olan hastalar çalışma dışı bırakıldı.

Plasentanın ayrılmasında fizyolojik yöntem esas alınd1. Doğum eylemi gerçekleştikten sonra plasentanın ayrılması için lohusaya kord traksiyonu, uterotonik ajanlar gibi müdahalelerde bulunulmad1. Plasentanın kendiliğinden, yer çekimi ve maternalefor ile spontan olarak ayrılması esas alındi. 5 dakika aralıklarla 30 dakikaya kadar vajinal tuşe yapılarak, plasentanın serviksten vajene düşüp düşmediği kontrol edildi. Serviksi geçtiği tespit edilen plasenta, ayrılmış olarak kabul edildi ve süreleri kaydedildi. 30 dakikada ayrılmayan plasentalar için kord traksiyonu, elle halas gibi müdahalelerde bulunularak plasentanın ayrılması sağlandı ve süresi 35 dakika olarak kayda geçildi.

Verilerin analizinde SPSS versiyon 15.0 programından yararlanılmıştır. Değişkenlerin normal dağılıma uygunluğu histogram grafikleri ve Kolmogorov-Smirnov testi ile incelendi. Tanımlay1c1 analizler sunulurken ortalama, standart sapma, ortanca ve minimum-maximum değerler kullanılmıştır. 2x2 gözlerde Pearson Ki Kare ve Fisher'ın Kesin Testleri ile karşılaştırıldı. Normal dağılım gösteren (parametrik) değişkenler gruplar arasında değerlendirilirken Bağımsız gruplarda $T$ Testi, normal dağ $11 ı \mathrm{~m}$ göstermeyenler (nonparametrik) gruplar arasında değerlendirilirken Mann Whitney U Testi kullanılmıştır. Ölçümsel verilerin birbirleri ile analizinde Spearman Korelasyon Testi'nden faydalanılmıştır. P-değerinin 0.05 'in altında olduğu durumlar istatistiksel olarak anlamlı sonuçlar şeklinde değerlendirildi.

\section{BULGULAR}

Çalışmaya katılan 198 hastanın demografik özellikleri Tablo 1 ve 2'de görülmektedir.

Tablo 1: Katılımcıların demografik değişkenleri.

\begin{tabular}{|l|l|l|l|l|}
\hline & Ortalama & \pm ss & Minimum & Maximum \\
\hline $\begin{array}{l}\text { Yaş } \\
\text { (y1l) }\end{array}$ & 27,08 & 6,14 & 15,00 & 44,00 \\
\hline $\begin{array}{l}\text { Doğum } \\
\text { sayıs1 }\end{array}$ & 1,31 & 1,38 & 0,00 & 8,00 \\
\hline $\begin{array}{l}\text { Abort } \\
\text { sayıs1 }\end{array}$ & 0,26 & 0,70 & 0,00 & 4,00 \\
\hline $\begin{array}{l}\text { Gebelik süresi } \\
\text { (hafta) }\end{array}$ & 39,41 & 1,34 & 35,60 & 42,20 \\
\hline $\begin{array}{l}\text { Sigara } \\
\text { (paket-yıl) }\end{array}$ & 0,24 & 1,33 & 0,00 & 10,00 \\
\hline $\begin{array}{l}\text { Bebek Ağırlığ1 } \\
\text { (g) }\end{array}$ & 3294,56 & 380,89 & 1985,00 & 4150,00 \\
\hline $\begin{array}{l}\text { Bebek Boyu } \\
\text { (cm) }\end{array}$ & 49,91 & 2,08 & 43,00 & 55,00 \\
\hline $\begin{array}{l}\text { Plasental Ayrılma } \\
\text { (dk.) }\end{array}$ & 11,69 & 6,09 & 5,00 & 35,00 \\
\hline
\end{tabular}

Tablo 2: Katılımcıların plasental yerleşim, sigara-alkol kullanımı, indüksiyon, amniotomi ve epizyotomi yapılma durumu ve bebeğin cinsiyetine göre dağılımı.

\begin{tabular}{|c|c|c|c|}
\hline & & $\mathrm{N}$ & $\%$ \\
\hline \multirow{5}{*}{ Plasental yerleşim } & Anterior & 104 & $(52,5)$ \\
\hline & Posterior & 79 & $(39,9)$ \\
\hline & Sağ lateral & 6 & $(3,0)$ \\
\hline & Sol lateral & 5 & $(2,5)$ \\
\hline & Fundus & 4 & $(2,0)$ \\
\hline \multirow{2}{*}{ Sigara-alkol kullanımı } & Evet & 188 & $(94,9)$ \\
\hline & Hayır & 10 & $(5,1)$ \\
\hline \multirow{2}{*}{ İnduksiyon } & Yapıldı & 110 & $(55,6)$ \\
\hline & Yap1lmad 1 & 88 & $(44,4)$ \\
\hline \multirow{2}{*}{ Amniotomi } & Yap1lmadi & 100 & $(50,5)$ \\
\hline & Yapıldı & 98 & $(49,5)$ \\
\hline \multirow{2}{*}{ Epizyotomi } & Yapılmadı & 125 & $(63,1)$ \\
\hline & Yapıldı & 73 & $(36,9)$ \\
\hline \multirow{3}{*}{ Bebek Cinsiyeti } & Erkek & 96 & $(48,5)$ \\
\hline & $\mathrm{K} 1 \mathrm{z}$ & 102 & $(51,5)$ \\
\hline & Toplam & 198 & $(100,0)$ \\
\hline
\end{tabular}

Yaş, abort sayısı, gebelik haftası, sigara kullanımı, bebeğin boyu ve ağırlığının plasental ayrılma süresini etkilemediği görülmüştür.

Çalışmaya dahil edilen 198 hastadan 193'ünün 30 dakika içerisinde plasental ayrılması gerçekleşti. Geriye kalan 5 hastaya 30 dakika içerisinde ayrılma gerçekleşmediğinden müdahalede bulunulup elle halas yapıldı. Tablo 9' da görüldüğü üzere hastaların $\% 96$ 'sının 20 dakika içerisinde plasental ayrılması gerçeklești. 20 dakika üzeri plasental ayrılması olan 8 hastanın 5'ine elle halas yapıld 1 ve bu da $\% 62.5$ olarak göze çarptı (Tablo 3).

Tablo 3: Plasenta ayrılma süresi hasta dağılımı.

\begin{tabular}{|c|c|c|}
\hline & $\mathrm{n}$ & $\%$ \\
\hline $0-5 \mathrm{dk}$ & 45 & 22,7 \\
\hline $5-10 \mathrm{dk}$ & 83 & 41,9 \\
\hline $10-15 \mathrm{dk}$ & 48 & 24,2 \\
\hline $15-20 \mathrm{dk}$ & 14 & 7,1 \\
\hline $20-25 \mathrm{dk}$ & 1 & 0,5 \\
\hline $25-30 \mathrm{dk}$ & 2 & 1,0 \\
\hline$>30 \mathrm{dk}$ & 5 & 2,5 \\
\hline Total & 198 & 100,0 \\
\hline
\end{tabular}

Katılımcıların epizyotomi, indüksiyon ve amniotomi uygulanması ile yaş, doğum sayısı, abort sayısı, plasental yerleşim, sigara-alkol kullanımı, kullandığı sigara paket-yıl1, ve bebeğin cinsiyeti, ağırlığı, boyu ile karş1laştırıldı. İndüksiyon veya amniotomi uygulanan ve uygulanmayanlarda anlamlı bir fark izlenmedi. Epizyotomi yapılmayanlarda yap1lanlara göre sadece yaş $(28,8 / 24,1)$, doğum sayıs1 $(1,93 / 0,26)$ ve bebek ağırlığı $(3364 / 3174)$ anlamlı yüksek bulundu $(\mathrm{p}<0,05)$. 
Katılımcıların indüksiyon yapılanların ve epizyotomi yapılmayanların plasental ayrılma süresi diğerlerine göre anlamlı olarak düşük olduğu saptanmıştır $(\mathrm{p}<0,05)$ (Tablo 4).

Tablo 4: Katılımcıların plasental yerleşimi, sigara-alkol kullanımı, bebeklerinin cinsiyetine göre plasental ayrılma süresi ortalamasının karşılaştırılması.

\begin{tabular}{|c|c|c|c|c|}
\hline & & \multicolumn{2}{|c|}{$\begin{array}{c}\text { Plasental } \\
\text { Ayrılma Süresi (dk.) }\end{array}$} & \multirow{2}{*}{$\mathrm{P}$} \\
\hline & & Ortalama & $\begin{array}{c}\text { Standart } \\
\text { Sapma }( \pm)\end{array}$ & \\
\hline \multirow{5}{*}{$\begin{array}{l}\text { Plasental } \\
\text { Yerleşim }\end{array}$} & Anterior & 11,73 & 5,65 & \multirow{5}{*}{$0.465^{b}$} \\
\hline & Posterior & 11,65 & 6,54 & \\
\hline & Sağ Lateral & 15 & 10 & \\
\hline & Sol Lateral & 11 & 2,24 & \\
\hline & Fundus & 7,5 & 2,89 & \\
\hline \multirow[t]{2}{*}{ İnduksiyon } & Yapılmadı & 12,56 & 6,16 & \multirow{2}{*}{$0.016^{\mathrm{a}}$} \\
\hline & Yapıldı & 11 & 5,97 & \\
\hline \multirow[t]{2}{*}{ Amniotomi } & Yapılmadı & 11,8 & 5,84 & \multirow{2}{*}{$0.582^{a}$} \\
\hline & Yapıldı & 11,58 & 6,37 & \\
\hline \multirow[t]{2}{*}{ Epizyotomi } & Yapılmadı & 11,16 & 6,13 & \multirow{2}{*}{$0.021^{\mathrm{a}}$} \\
\hline & Yapıldı & 12,6 & 5,96 & \\
\hline \multirow{2}{*}{$\begin{array}{l}\text { Sigara-alkol } \\
\text { Kullanımı }\end{array}$} & Evet & 11,65 & 5,96 & \multirow{2}{*}{$0.938^{\mathrm{a}}$} \\
\hline & Hayır & 12,5 & 8,58 & \\
\hline \multirow{2}{*}{$\begin{array}{l}\text { Bebek } \\
\text { Cinsiyet }\end{array}$} & Erkek & 11,56 & 5,44 & \multirow{2}{*}{$0.764^{\mathrm{a}}$} \\
\hline & $\mathrm{K} 1 \mathrm{z}$ & 11,81 & 6,67 & \\
\hline
\end{tabular}

a : Mann-Whitney U testi, b : KruskalVallis testi.

Korelasyon matrisine bakıldığında plasental ayrılma süresi ile doğum sayısı arasında düşük düzeyde $($ rho $=-0,196)$, ancak anlaml $(\mathrm{p}=0.006)$ bir negatif korelasyon bulunmuştur. Buna göre hastaların doğum sayısındaki artış ile plasental ayrılma süresinin azaldığı gözlenmiştir (Şekil 1).

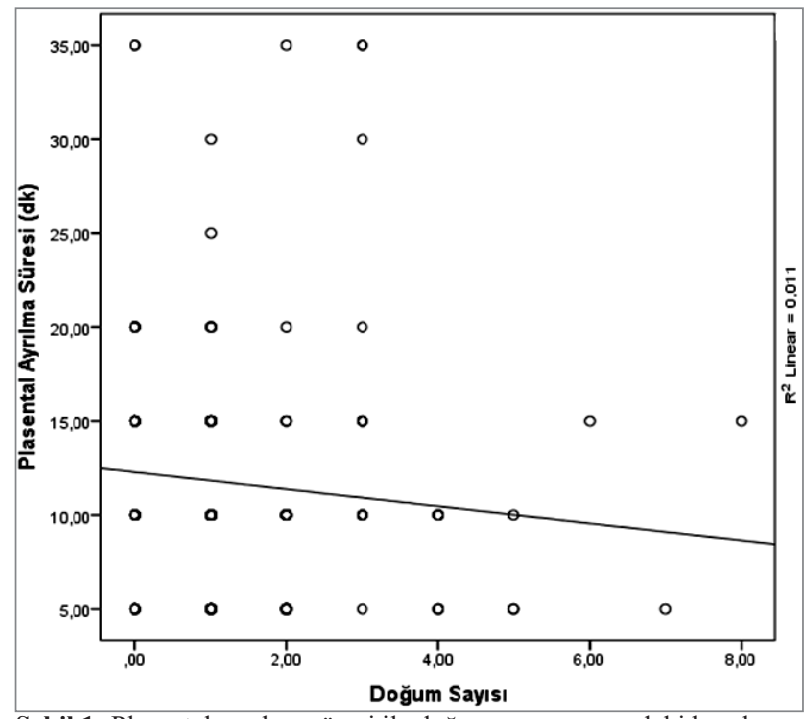

Sekil 1: Plasental ayrılma süresi ile doğum sayısı arasındaki korelasyon grafiği.

Bebeğin ağırlığı ile doğum sayısı arasında ise pozitif ve düşük düzeyde bir korelasyon saptanmıştır ve bu bulgu da istatistiksel olarak çok anlamlıdır $(\mathrm{rho}=0.293, \mathrm{p}<0.001)$. Bu sonuç doğum sayısı arttıkça doğan bebeğin ağırlığının arttığını düşündürmektedir. Plasenta yerleşim yerinin süreyi etkilemediği izlendi.
Epizyotomi ile plasental ayrılma süresi arasındaki anlamlı ilişkinin öncesinde doğum olmasına göre tabakalandırıldığında kaybolduğu saptanmıştır. Buna göre epizyotomi yapılan hastalarda plasenta ayrılma zamanını etkileyen faktör, bu hastaların aynı zamanda doğum sayısının azlığından kaynaklandığ düşünülmektedir (Tablo 5).

Tablo 5: Doğum sayıları ve epizyotomi durumuna göre plasenta ayrilma süresi.

\begin{tabular}{|c|c|c|c|c|c|}
\hline & \multicolumn{4}{|c|}{ Epizyotomi } & \\
\hline & \multicolumn{2}{|c|}{ Yapılmadı } & \multicolumn{2}{|c|}{ Yapıldı } & \\
\hline & \multicolumn{2}{|c|}{$\begin{array}{c}\text { Plasental Ayrılma } \\
\text { Süresi }\end{array}$} & \multicolumn{2}{|c|}{$\begin{array}{c}\text { Plasental Ayrilma } \\
\text { Süresi }\end{array}$} & \multirow[t]{2}{*}{$\mathrm{P}$} \\
\hline & Ortalama & \pm ss & Ortalama & $\pm \mathrm{ss}$ & \\
\hline $\begin{array}{l}\text { Öncesinde } \\
\text { doğum yok }\end{array}$ & 11,25 & 2,5 & 12,97 & 6,17 & 0,594 \\
\hline $\begin{array}{l}\text { Öncesinde } \\
\text { doğum var }\end{array}$ & 11,16 & 6,22 & 11,07 & 4,87 & 0,671 \\
\hline
\end{tabular}

\section{TARTIŞMA}

Doğumun 3. evresiyle ilgili çalışmalar büyük ölçüde ihmal edilmiştir ve bu evredeki olaylar genelde belirsiz varsayımlardır. Doğumun 3. evresi en tehlikeli dönemi temsil ediyor olsa da, bu dönem net olarak anlaşılamamıştır.

Plasentanın spontan doğması genelde bebeğin doğumunu izleyen 10 dakika içinde gerçekleşir. Combs ve Laros, 11 yıl süren bir çalışmada 12979 tekiz vajinal doğumu incelemiş̧ler ve doğumun üçüncü evresinin ortalama 6 dakika (4-10 dakika) sürdüğünü göstermişler (3). Plasentanın ayrılma süresi literatürde genel olarak 4 ile 15 dakika aral1ğında olduğunu gözlemledik. Biz de çalışmamızda bu süreyi literatür ile uyumlu olarak $11.69 \pm 6.09 \mathrm{dk}$ olarak tespit ettik.

Doğumun üçüncü evresinin süresi 30 dakika üzerine çıkmadığ 1 sürece uzamadan genelde bahsedilmez. Üçüncü evrenin $30 \mathrm{dk}$ 'y1 geçme prevalans1 literatürde \%2.2-3.3 gibi değerlerde arasındadır (3, 4). Biz prospektif gözlemsel olarak yaptı̆̆ımız bu çalışmamızda \%2.5 (n:5) olarak benzer oranda bulduk. Çalışmamızda plasental ayrılmanın \%96'sının 20 dakikada gerçekleşti düşünülürse 3. evre için 30 dakika olarak genel kabul gören eşik değer belki de daha geniş çaplı randomize çalışmalar ile değiştirilebilir.

Plasentanın ayrılma süresini etkileyen faktörlere baktığımızda, literatürde aktif yönetimin doğumun 3 . evresinde uygulandığında bu süreyi kısaltan indüksiyon yöntemlerinin olduğu gösterilmiştir. Yuenve ark.serilerinde üçüncü evrenin süresini çalışmamızın süresine benzer bulmuşlar ve değişik uterotonik ajanların kullanılmasına bağlı farklı uzamış üçüncü evre hızları izlemişler (5). Taebi ve ark. 1000 serilik çalışmalarında doğum indüksiyonunun plasenta ayrilma süresini uzattı̆̆ını tespit etmişler (6). Sürenin kısaldığına dair çalışmalarda mevcuttur (7). İndüksiyon amaçlı sadece oksitosin kullandığımız çalışmamızda indüksiyon uygulananlarda 3. evre süresinin anlamlı olarak daha kısa olduğunu tespit ettik $(11 \pm 5,97 \mathrm{dk}$ ve $12,56 \pm 6,16 \mathrm{dk}$; sirasiyla, p:0,016). 
Daha önce doğum yapmış hastalarda da bu sürenin kısaldığı bulduğumuz diğer bir faktörken abort sayısının ayrılma süresini etkilemediğini fark ettik. Taebi ve ark. çalışmamıza benzer olarak parite arttıkça sürenin kısaldığını ancak abort sayısıyla ilişkisinin olmadığını tespit etmişler (6). Zhou ve ark ise artan abort sayısının süreyi kısalttığına dair zayıf bir ilişki tespit etmişler (8).

Doğum sayısındaki artış ile epizyotomi yapılmayanlar arasındaki anlamlı farkı da değerlendirdiğimizde, epizyotomi yapılmayanların plasenta ayrılma süresini kısalttığına dair çıkan istatistiki veri de bu bulgunun doğum sayısının artmasıyla ilişkili olduğunu göstermektedir. Yani epizyotominin plasenta ayrilma süresi üzerinde direk etkisinin olmadığ1 sonucuna vard1k. Frolova ve ark. vajinal doğumlarla operatif doğumları karşılaştırdıklarında 3. Evre zamanında fark izlememişler (9). Literatürde epizyotomiyle ilişkisinin açıkça değerlendirildiği bir çalışmaya rastlanmadı.

Plasental yerleşimin plasenta ayrılma süresine etkisiyle ilgili sınırlı literatür bilgisi mevcuttur. Biz çalışmamızda anlamlı bir fark izlemezken Lurie ve ark. Fundal yerleşimli plasentanın ön, arka ve yan yerleşimli plasentalara oranla daha uzun sürede ayrildığını ve bunun anlamlı olduğunu izlemişler (10). Yeni Zelanda Ebeler Birliği'nin 2009 yılında yayınladıkları retrospektif kohort çalışmasında, doğumun birinci ve ikinci evresi normal geçen 33752 gebe değerlendirilmiş ve fizyolojik yönetimde ortalama kan kaybının aktif yönetime göre daha az olduğu izlenmiş. Fizyolojik yönetimin tecrübeli ellerde ve normal bir doğum sürecini takriben uygulanmas1, postpartum kanama riskinde azalma ile ilişkili olduğu düşünülmüş $(11,12)$.

Çalışmamızda aktif ve fizyolojik yöntemin karş1laştırılmamış olması ve postpartum kanama değerlerinin değerlendirilmemiş olması eksikliklerimiz arasinda sayılabilir.

\section{SONUÇ}

Artan parite sayısı ve indüksiyon uygulaması plasenta ayrılma zamanını kısalmaktadır. Plasenta ayrılmasında gecikme yaşandığında ek müdahale için ne kadar beklenmesi gerektiğiyle ilgili geniş çaplı araştırmalar yapılabilir.

\section{KAYNAKLAR}

1. Hibbard BM. Obstetics in general practice. The third stage of labour. Br Med J 1964; 5396:1485.

2. Khan KS, Wojdyla D, Say L, et al. WHO analysis of causes of maternal death: a systematic review. Lancet 2006; 367: 1066-10.

3. Combs CA, Laros RK. Jr. Prolonged third stage of labor: Morbidity and risk factors. ObstetGynecol 1991; 77(6): 863-7.

4. Dombrowski MP, Bottoms SF, Saleh AA, Hurd WW, Romero R. Third satage of labor analysis of duration and clinical practice. Am J ObstetGynecol 1995; 172:1279-84.

5. Yuen PM, Chan NST, Yim SF, Chang AMZ. A randomised double blind comparison of Syntometrine and Syntocinon in the management of the third stage labor. BJOG 1995; 102(5): 377-80.

6. Taebi M, Abedzadeh M.K, Saberi F, Sadat Z. Theduration of thethirdstage of laborandrelatedfactors. Iran J NursMidwiferyRes. 2012 Feb; 17(2 Suppl1): S76-S79.

7. Panpaprai P, Boriboonhirunsarn D. Risk factors of retainedplacenta in SirirajHospital. J MedAssocThai. 2007;90(2 Suppl1):1293-7.

8. Zhou W, Nielsen GL, Larsen H, Olsen J. Inducedabortionandplacentacomplications in thesubsequentpregnancy. ActaObstetGynecolScand. $2001 ; 80(12): 1115-20$

9. Frolova AI, Stout MJ, Tuuli MG, López JD, Macones GA, Cahill AG. Duration of the Third Stage of Laborand Risk of PostpartumHemorrhage.nObstetGynecol. 2016 May;127(5):951-6.

10. Lurie S, Gomel A, Adan O, Ginath S, Rotmensch S, Glezerman M. TheDuration of the Third Stage of Labor Is Subject to the Location of Placental Implantation. Gynecol Obstet Invest 2003;56:14-16.

11. New Zealand College of Midwives. Third stage management practices of midwife lead maternity carers: an analysis of the New Zealand College of Midwives Midwifery Database Information 2004 -2008. Christchurch: New Zealand College of Midwives, 2009.

12. Begley CM, Gyte CML, Murphy DJ, Devane D, McDonald SJ, McGuire $W$. Active versus expectant management for women in the third stage of labor, Cochrane Database Syst Rev Issue 7, 2010. 